Research Article

\title{
Parameter Analysis of an Intershaft Dual-Rotor with the Application of Squeeze Film Dampers
}

\author{
Huizheng Chen, ${ }^{1}$ Shun Zhong $\mathbb{D}^{2},{ }^{2}$ Zhenyong Lu, ${ }^{1}$ Yushu Chen, ${ }^{2}$ and Xiyu Liu ${ }^{1}{ }^{1}$ \\ ${ }^{1}$ Institute of Dynamics and Control Science, Shandong Normal University, Jinan 250014, China \\ ${ }^{2}$ Department of Mechanics and Key Laboratory of Nonlinear Dynamics and Control, Tianjin University, Tianjin 300072, China
}

Correspondence should be addressed to Shun Zhong; shunzhong@tju.edu.cn

Received 29 July 2021; Accepted 2 September 2021; Published 14 September 2021

Academic Editor: Yong-Feng Yang

Copyright (c) 2021 Huizheng Chen et al. This is an open access article distributed under the Creative Commons Attribution License, which permits unrestricted use, distribution, and reproduction in any medium, provided the original work is properly cited.

\begin{abstract}
The squeeze film damper is usually adopted in the rotor system to suppress the vibrating motion of the rotor system. In this work, not only are the physical parameters of the squeeze film damper analyzed but also the system parameters, like the number of squeeze film dampers used and squeeze film damper implementation positions, are analyzed. The amplitude-frequency curves are obtained by conducting the simulation of a dual-rotor, intershaft, and oil film force concatenated model. Through the analysis and comparisons of the results, the vibration suppression effects of the squeeze film damper with different parameter configurations are analyzed and summarized. This work contributes to further optimization and dynamical analysis work on rotor systems with the application of the squeeze film damper.
\end{abstract}

\section{Introduction}

Among various types of aeroengines [1-3], turbofan engines are relatively common and draw much research attention [4-9]. The typical structure of turbofan engines is a dual-rotor structure with a low-pressure rotor and a high-pressure rotor. In most of the dual-rotor designs, the high- and the low-pressure rotors are connected by intershaft bearings $[10,11]$. The nonlinear factor introduced by the intershaft leads the research on dual-rotor system to be more complex. And in the engineering field, many damping structures are adopted. The squeeze film damper (SFD) is one of them.

As a support structure with a damping function, the SFD has been widely used in aeroengines due to its small size and lightweight and has even become a standard configuration in the design. Many researchers focused on the design of SFD and its application effects to the rotor system. Shaik and Dutta $[12,13]$ purposed a close form solution to find the nonlinear tuning parameters of symmetric/asymmetric rotor-squeeze film damper system. They also dealt with the development of a close form solution to find the stability of flexible symmetric horizontal rigid and tuned flexible rotor mounted on hydrodynamic bearing with squeeze film damper system. Zhang et al. [14] presented a multiobjective optimal design method for a squeeze film damper with centring spring. The proposed method was able to obtain the optimal design parameters for a flexible rotor system. Zheng et al. [15] proposed a controllable clearance squeeze film damper which used hydraulic pressure to adjust the radial clearance and established a corresponding test rig. Ma et al. [16] emphasized the comparative analysis of the influence of SFD on the nonlinear dynamic behavior of the dual-rotor system supported by rolling bearings. Fan and Behdinan [17] investigated the effect of a circumferential central groove on an open-ended squeeze film damper analytically. Shin et al. [18] treated the unconventional application of the SFD for the mitigation of Morton effect induced vibration. Chen et al. [19] investigated dynamic characteristics of rotor system mounted on aircraft during maneuvering flights. Iacobellis et al. [20] designed and built SFD-rotor test rig to study the effect of SFD oil supply pressure, oil temperature, oil inlet feed number/orientation, unbalance, and seals on the response of a Jeffcott rotor. Li et al. [21] manufactured 
and tested a pair of 3.5-inch SFD bearings to validate a new squeeze film damper bearing design.

It is noting that because the nonlinear factor exists in the rotor system, especially with the application of intershaft bearing and SFD, the analytical solution is hardly obtained. Thus, most of the related research work adopted numerical methods and experimental methods to solve the problem. However, to allow a deeper insight into the physics of the problem, many researchers tried their best to propose some analytical methods to investigate the problem. For example, Curti et al. [22] proposed an analytical procedure, based on the dynamic stiffness method for the study of rotor dynamics problems. Herisanu and Marinca [23] proposed the optimal auxiliary functions method to deal with the analytical investigation of a multirotor system connected by a flexible coupling subjected to dynamic angular misalignment. The proposed method was proved to be successfully used to obtain explicit analytical solutions to a system of strongly nonlinear differential equations with variable coefficients, useful in dynamic analysis of the considered multirotor system. Fan et al. [24] used the transfer matrix method to investigate the dual-motor coupling drive system analytical and verified the results by experiment. These methods provide us an alternative way to investigate the problem.

To further investigate the dynamical behaviors and achieve better or desired performances of the rotor systems with SFD, the design of the parameters of the SFD need focused attention. Meanwhile, the installation positions of squeeze film dampers also have different effects on the overall vibration of the rotor. Different implementation positions and different parameters may lead to different results. Therefore, this work will focus on the analysis of the parameters of the SFD and their introduced effects on the rotor system. The parameters not only include the physical parameters of the SFD, such as clearance, but also general parameters like the implementation positions and the number of SFD used. The paper is organized as follows: in Section 2, a dual-rotor system model with SFD mounted on the intershaft bearing is established. The detailed modeling processes of the bearing and oil force are described. In
Section 3, the parameter analysis is conducted. Comparison results of different parameters set are given out. Finally, the results are discussed and concluded.

\section{Modeling of an Inter-Shaft Bearing Dual-Rotor System with the Application of SFD}

2.1. Dual-Rotor Model. Figure 1 shows a dual-rotor system, in which the high-pressure shaft is outside the low-pressure shaft. The low-pressure rotor is supported by two rolling bearing elastic support structures at each end of the lowpressure shaft. The high-pressure rotor is connected directly with the base by a rolling bearing and an elastic structure at the left end and through an intershaft bearing at the other end with the low-pressure shaft. The SFDs can be implemented on any rolling bearings according to the needs. When elastic support structure is applied, the stiffness of the whole support node is dominated by the stiffness of elastic support. Compared with the stiffness of the elastic support structure usually adopted in aeroengines, the stiffness of the rolling bearing is large enough to be neglected in the calculation. Then, the governing equations of the dual-rotor system could be established by Newton's law as follows: where subscript 1 represents low-pressure rotor and subscript 2 represents high-pressure rotor. $x$ represents the horizontal displacement of the disc center and $y$ means the vertical displacement of the disc center. $J_{p}$ means the polar moment of inertia and $J_{d}$ the equatorial moment of inertia of the disc. $\delta$ means eccentricity. $\omega_{i}=2 \pi f_{i}$ represent the angle rotation frequencies of the low- and high-pressure rotors and $f_{i}$ frequencies. $\theta_{x}$ is the rotation angle of the lowpressure disc along the $x$-axis and $\theta_{y}$ the rotation angle of the low-pressure disc along the $y$-axis. $\varphi_{x}$ is the rotation angle of the high-pressure disc along the $x$-axis and $\varphi_{y}$ the rotation angle of the high-pressure disc along the $y$-axis. $c_{i}(i=1,2,3)$ are the damping coefficients of the structure. $F_{b}$ is the intershaft bearing force. $F_{1}$ represents the low-pressure rotor oil film force and $F_{2}$ the high-pressure rotor oil film force. $M_{1}$ is the torque produced by the low-pressure rotor oil film and $M_{2}$ the torque produced by the high-pressure rotor oil film. 


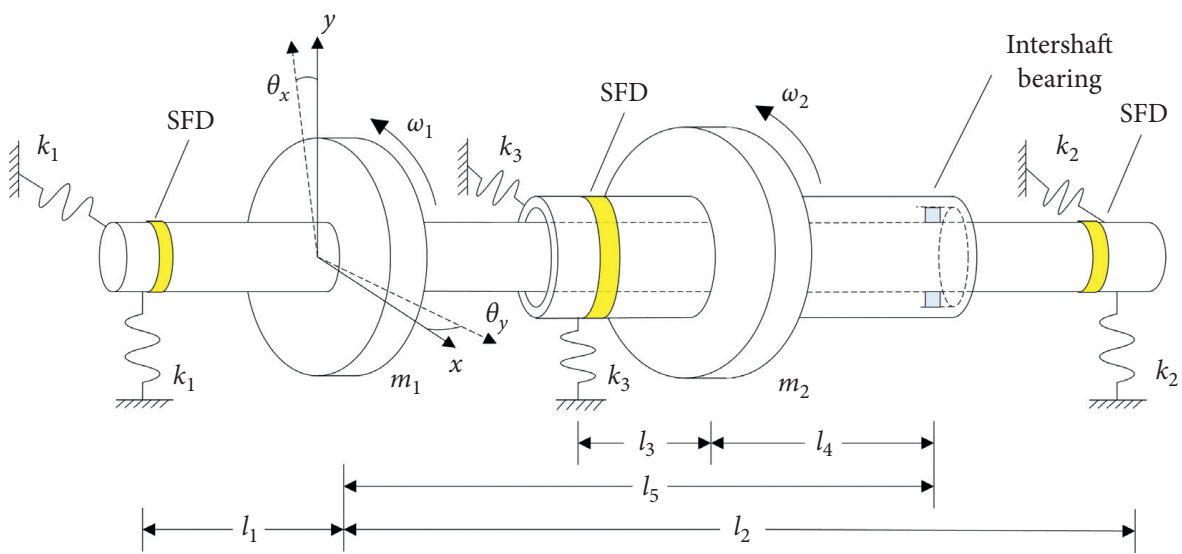

FIgURE 1: Schematic diagram of the dual-rotor system with intershaft bearing.

$$
\left\{\begin{array}{l}
m_{1} \ddot{x}_{1}+c_{1}\left(\dot{x}_{1}+l_{1} \dot{\theta}_{y}\right)+c_{2}\left(\dot{x}_{1}-l_{2} \dot{\theta}_{y}\right)+k_{1}\left(x_{1}+l_{1} \theta_{y}\right) \\
+k_{2}\left(x_{1}-l_{2} \theta_{y}+F_{b x}+F_{1 x}=m_{1} \delta_{1} \omega_{1}^{2} \cos \omega_{1} t\right. \\
m_{1} \ddot{y}_{1}+c_{1}\left(\dot{y}_{1}-l_{1} \dot{\theta}_{x}\right)+c_{2}\left(\dot{y}_{1}+l_{2} \dot{\theta}_{x}\right)+k_{1}\left(y_{1}-l_{1} \theta_{x}\right) \\
+k_{2}\left(y_{1}+l_{2} \theta_{x}+F_{b y}+F_{1 y}=m_{1} \delta_{1} \omega_{1}^{2} \sin \omega_{1} t-m_{1} g\right. \\
J_{d 1} \ddot{\theta}_{x}+J_{p 1} \omega_{1} \dot{\theta}_{y}-c_{1} l_{1}\left(\dot{y}_{1}-l_{1} \dot{\theta}_{x}\right)+c_{2} l_{2}\left(\dot{y}_{1}+l_{2} \dot{\theta}_{x}\right) \\
-k_{1} l_{1}\left(y_{1}-l_{1} \theta_{x}\right)+k_{2} l_{2}\left(y_{1}+l_{2} \theta_{x}\right)+F_{b y} l_{5}+M_{1 x}=0 \\
J_{d 1} \ddot{\theta}_{y}-J_{p 1} \omega_{1} \dot{\theta}_{x}+c_{1} l_{1}\left(\dot{x}_{1}+l_{1} \dot{\theta}_{y}\right)-c_{2} l_{2}\left(\dot{x}_{1}-l_{2} \dot{\theta}_{y}\right) \\
+k_{1} l_{1}\left(x_{1}+l_{1} \theta_{y}\right)-k_{2} l_{2}\left(x_{1}-l_{2} \theta_{y}\right)-F_{b x} l_{5}+M_{1 y}=0 \\
m_{2} \ddot{x}_{2}+c_{3}\left(\dot{x}_{2}+l_{3} \dot{\varphi}_{y}\right)+k_{3}\left(x_{2}+l_{3} \varphi_{y}\right)-F_{b x}+F_{2 x}=m_{2} \delta_{2} \omega_{2}^{2} \cos \omega_{2} t \\
m_{2} \ddot{y}_{2}+c_{3}\left(\dot{y}_{2}-l_{3} \dot{\varphi}_{x}\right)+k_{3}\left(y_{2}-l_{3} \varphi_{x}\right)-F_{b y}+F_{2 y}=m_{2} \delta_{2} \omega_{2}^{2} \sin \omega_{2} t-m_{2} g \\
J_{d 2} \ddot{\varphi}_{x}+J_{p 2} \omega_{2} \dot{\varphi}_{y}-c_{3} l_{3}\left(\dot{y}_{2}-l_{3} \dot{\varphi}_{x}\right)-k_{3} l_{3}\left(y_{2}-l_{3} \varphi_{x}\right)-F_{b y} l_{4}+M_{2 x}=0 \\
J_{d 2} \ddot{\varphi}_{y}-J_{p 2} \omega_{2} \dot{\varphi}_{x}+c_{3} l_{3}\left(\dot{x}_{2}+l_{3} \dot{\varphi}_{y}\right)+k_{3} l_{3}\left(x_{2}+l_{3} \varphi_{y}\right)+F_{b x} l_{4}+M_{2 y}=0
\end{array}\right.
$$

2.2. Intershaft Bearing Force Model. Consider that the intershaft bearing is a cylindrical roller bearing, whose structure is shown in Figure 2.

Assume that the inner and outer rings rotate in the same direction with angular speeds $\omega_{1}$ and $\omega_{2}$, respectively. The rollers roll along the inner and outer rings without sliding. Then, the speed of the cage can be expressed as

$$
\omega_{c}=\frac{\omega_{1} r_{i}+\omega_{2} r_{o}}{r_{i}+r_{o}}
$$

where $r_{i}$ represents the radius of the inner ring of the bearing and $r_{o}$ the radius of the outer ring of the bearing. At any moment, the movement position angle of each roller is

$$
\gamma_{i}=\frac{2 \pi(i-1)}{N_{b}+\omega_{c} t},
$$

where $N_{b}$ is the number of rollers and subscription $i=1 \ldots N_{b}$. If the horizontal and vertical displacement components of the inner and outer rings of the bearing are $x_{i}, x_{o}, y_{i}$, and $y_{o}$, respectively, the radial position relationship between the journal and each roller is

$$
\delta_{i}=\left(x_{i}-x_{o}\right) \cos \gamma_{i}+\left(y_{i}-y_{o}\right) \sin \gamma_{i}-\delta_{0},
$$

where $\delta_{0}$ is the radial clearance of the bearing.

According to the relationships of displacements and rotation angles at the connection points of high- and lowpressure rotors, there are

$$
\begin{aligned}
\delta_{i}= & \left(x_{1}-l_{5} \theta_{y}-x_{2}+l_{4} \varphi_{y}\right) \cos \gamma_{i} \\
& +\left(y_{1}+l_{5} \theta_{x}-y_{2}-l_{4} \varphi_{x}\right) \sin \gamma_{i}-\delta_{0} .
\end{aligned}
$$

If $\delta_{i}<0$, it means that the inner ring of the bearing is not in contact with the roller, and the roller does not provide contact force. While if $\delta_{i}>0$, it means that the inner ring of the bearing is in contact with the roller, and the roller provides Hertz contact force. According to the theory of bearing roller line contact theory [25], the bearing force can be expressed as 


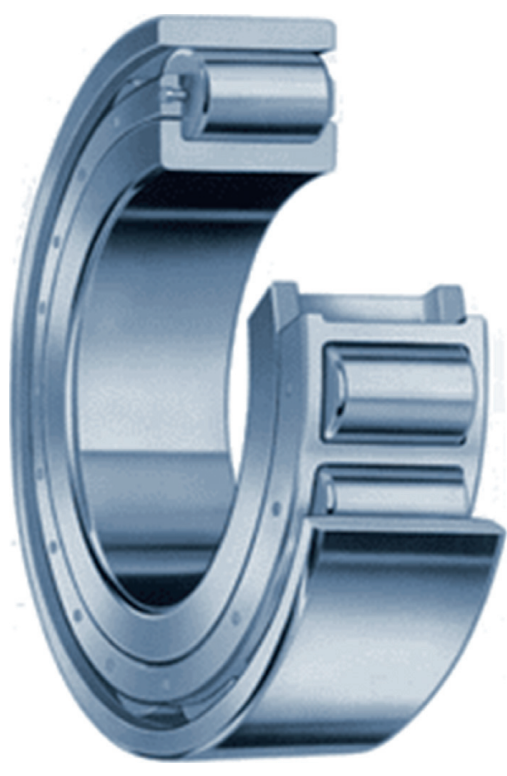

(a)

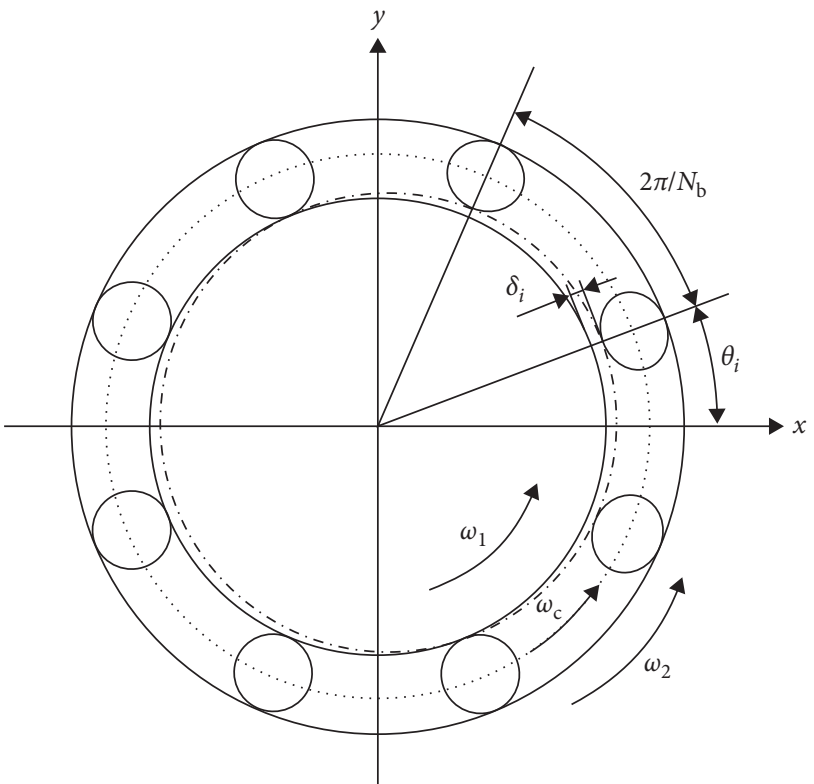

(b)

FIgURE 2: Schematic diagram of the intershaft bearing. (a) Structure of the bearing and (b) sketch in radial direction.

$$
\left[\begin{array}{l}
F_{b x} \\
F_{b y}
\end{array}\right]=C_{b} \sum_{i=1}^{N_{b}}\left(\delta_{i} H\left[\delta_{i}\right]\right)^{10 / 9}\left[\begin{array}{c}
\cos \gamma_{i} \\
\sin \gamma_{i}
\end{array}\right],
$$

in which $C_{b}$ is the Hertz contact stiffness and $H[\cdot]$ is Heaviside function.

2.3. Oil Film Force Model. With three possible implemented positions, the oil film forces can be expressed as

$$
\begin{aligned}
& F_{1 x}=\phi_{1} F_{c 1 x}+\phi_{2} F_{c 2 x}, \\
& F_{1 y}=\phi_{1} F_{c 1 y}+\phi_{2} F_{c 2 y}, \\
& F_{2 x}=\phi_{3} F_{c 3 x}, \\
& F_{2 y}=\phi_{3} F_{c 3 y} .
\end{aligned}
$$

And the corresponding moment term produced by the oil film is

$$
\begin{aligned}
& M_{1 x}=-\phi_{1} F_{c 1 x} l_{1}+\phi_{2} F_{c 2 x} l_{2}, \\
& M_{1 y}=\phi_{1} F_{c 1 y} l_{1}-\phi_{2} F_{c 2 y} l_{2}, \\
& M_{2 x}=-\phi_{3} F_{c 3 x} l_{3}, \\
& M_{2 y}=-\phi_{3} F_{c 3 y} l_{3} .
\end{aligned}
$$

According to the short bearing approximate model in equations (7) and (8),

$$
\begin{aligned}
& F_{c i x}=F_{i r} \cos \psi_{i}-F_{i \tau} \sin \psi_{i}, \\
& F_{c i y}=F_{i r} \sin \psi_{i}+F_{i \tau} \cos \psi_{i},
\end{aligned}
$$

where

$$
\begin{gathered}
F_{i r}=\frac{\mu_{i} R_{i} L_{i}^{3}}{c l_{i}^{3}\left(I_{i}^{02} \dot{e}_{i}+I_{i}^{11} e_{i} \dot{\psi}_{i}\right)}, \\
F_{i \tau}=\frac{\mu_{i} R_{i} L_{i}^{3}}{c l_{i}^{3}\left(I_{i}^{11} \dot{e}_{i}+I_{i}^{20} e_{i} \dot{\psi}_{i}\right)},
\end{gathered}
$$

where subscript $i=1,2,3 . c l_{i}$ is the thicknesses of the oil films. $e_{i}$ is the radial displacement of the journal center at each support, and its expression is

$$
e_{i}=\sqrt{x_{J i}^{2}+y_{J i}^{2}}
$$

where

$$
\begin{aligned}
& x_{J 1}=x_{1}+l_{2} \theta_{y}, \\
& x_{J 2}=x_{1}-l_{2} \theta_{y}, \\
& x_{J 3}=x_{2}+l_{3} \varphi_{y}, \\
& y_{J 1}=y_{1}-l_{1} \theta_{x}, \\
& y_{J 2}=y_{1}+l_{2} \theta_{x}, \\
& y_{J 3}=y_{2}+l_{3} \varphi_{x} .
\end{aligned}
$$

$\psi_{i}$ is the whirl angle of each journal. The expression is

$$
\psi_{i}=\arctan \left(\frac{y_{J i}}{x_{J i}}\right) .
$$

$\mu_{i}$ is the viscosity coefficient of the lubricating oil at each journal. $R_{i}$ is the radius of each journal bearing. $L_{i}$ is the length of each damper. $\phi_{1}, \phi_{2}$, and $\phi_{3}$ indicate whether the corresponding SFD is installed and 


$$
I_{i}^{l m}=\int_{\theta_{1}}^{\theta_{2}} \frac{\sin ^{l} \theta \cos ^{m} \theta}{\left(1+e_{i} \cos \theta / c l_{i}\right)^{3}} \mathrm{~d} \theta,
$$

is the Sommerfeld coefficient.

\section{Parameter Analysis}

Given the parameters of the system which are listed in Table 1, the simulation of equation (1) by the Runge-Kutta method is conducted.

In the dual-rotor system described by equation (1), the intershaft bearing provides nonlinear changeable restoring forces. Thus, the equivalent stiffness has a time-varying feature [26] and rotating speed-dependent feather [27], which is shown in Figure 3. Usually, the derivatives of forces with respect to corresponding displacements, that is, $\partial F_{b x} / \partial x$ and $\partial F_{b x} / \partial y$, are considered to be the equivalent stiffnesses in the horizontal and vertical directions at any time. Also, with different excitation frequencies, the horizontal and vertical stiffnesses vary in different ranges but both fluctuate periodically within a certain range. Therefore, the equivalent stiffness at a specific frequency can be estimated by the average value of the derivatives during a sampling length:

$$
\begin{aligned}
& k_{b x}=\frac{1}{N} \sum_{i=1}^{N} \frac{\partial F_{b x}}{\partial x_{1}}(i \triangle t), \\
& k_{b y}=\frac{1}{N} \sum_{i=1}^{N} \frac{\partial F_{b y}}{\partial y_{1}}(i \triangle t),
\end{aligned}
$$

where $N=T / \Delta t$ is the number of discrete points of numerical integration.

Based on the calculation method described in equation (15), the equivalent stiffnesses can be calculated. The natural frequencies and corresponding models of the system could be estimated. When $\delta_{0}=30 \mu \mathrm{m}$, the first two natural frequencies of the system are $61.9 \mathrm{~Hz}$ and $95 \mathrm{~Hz}$. The corresponding models are shown in Figure 4.

3.1. Analysis of the Bearing Clearance. Because different bearing parameters and rotating frequencies would lead the damping effect of the SFD to change, Figure 5 gives the amplitude-frequency response curves of the high- and lowpressure rotors in the horizontal direction with different bearing clearances. The high- and low-pressure rotors' amplitude-frequency responses are consistent. The resonance peaks appear when $f_{1}=46.3 \mathrm{~Hz}, f_{1}=60.7 \mathrm{~Hz}$, $f_{1}=72.1 \mathrm{~Hz}$, and $f_{1}=95.5 \mathrm{~Hz}$. In the case of $f_{1}=46.3 \mathrm{~Hz}$ and $f_{2}=60.2 \mathrm{~Hz}$, which corresponds to the first-order natural frequency of the system. This is the high-pressure introduced first-order resonance. The frequency components of the responses are shown in Figures 6(a) and 6(b). When $f_{1}=60.7 \mathrm{~Hz}$, the low-pressure rotor introduced firstorder resonance occurs. Similarly, the frequency components are shown in Figures 6(c) and 6(d). In the cases of $f_{1}=72.1 \mathrm{~Hz}$ and $f_{1}=95.5 \mathrm{~Hz}$, high- and low-pressure

\begin{tabular}{|c|c|}
\hline Para. & Values \\
\hline \multicolumn{2}{|c|}{ Rotor parameters } \\
\hline$m_{1}$ & $97.37 \mathrm{~kg}$ \\
\hline$m_{2}$ & $108.30 \mathrm{~kg}$ \\
\hline$l_{1}$ & $0.9188 \mathrm{~m}$ \\
\hline$l_{2}$ & $1.1122 \mathrm{~m}$ \\
\hline$l_{3}$ & $0.5120 \mathrm{~m}$ \\
\hline$l_{4}$ & $0.6243 \mathrm{~m}$ \\
\hline$l_{5}$ & $1.0127 \mathrm{~m}$ \\
\hline$J_{d 1}$ & $1.8454 \mathrm{~kg} \cdot \mathrm{m}^{2}$ \\
\hline$J_{p 1}$ & $3.6907 \mathrm{~kg} \cdot \mathrm{m}^{2}$ \\
\hline$J_{d 2}$ & $2.0060 \mathrm{~kg} \cdot \mathrm{m}^{2}$ \\
\hline$J_{p 2}$ & $4.0119 \mathrm{~kg} \cdot \mathrm{m}^{2}$ \\
\hline$k_{1}$ & $1.1 \times 10^{7} \mathrm{~N} / \mathrm{m}$ \\
\hline$k_{2}$ & $1.1 \times 10^{7} \mathrm{~N} / \mathrm{m}$ \\
\hline$k_{3}$ & $1.1 \times 10^{7} \mathrm{~N} / \mathrm{m}$ \\
\hline$c_{1}$ & $655 \mathrm{Ns} / \mathrm{m}$ \\
\hline$c_{2}$ & $655 \mathrm{Ns} / \mathrm{m}$ \\
\hline$c_{3}$ & $690 \mathrm{Ns} / \mathrm{m}$ \\
\hline$\delta_{1}$ & $1.5 \times 10^{-5} \mathrm{~m}$ \\
\hline$\delta_{2}$ & $1.0 \times 10^{-5} \mathrm{~m}$ \\
\hline \multicolumn{2}{|c|}{ Intershaft bearing parameters } \\
\hline$r_{i}$ & $58 \mathrm{~mm}$ \\
\hline$r_{o}$ & $66 \mathrm{~mm}$ \\
\hline$N_{b}$ & 34 \\
\hline$C_{b}$ & $1.0 \times 10^{9} \mathrm{~N} \cdot \mathrm{m}^{9 / 10}$ \\
\hline \multicolumn{2}{|c|}{ SFD parameters } \\
\hline$R_{1}$ & $65 \mathrm{~mm}$ \\
\hline$R_{2}$ & $72.5 \mathrm{~mm}$ \\
\hline$R_{3}$ & $119 \mathrm{~mm}$ \\
\hline$c l_{i}$ & $0.2 \mathrm{~mm}$ \\
\hline$L_{i}$ & $18 \mathrm{~mm}$ \\
\hline$\mu_{i}$ & $6.762 \times 10^{-3} \mathrm{Ns} / \mathrm{m}^{2}$ \\
\hline$\omega_{2} / \omega_{1}$ & 1.3 \\
\hline
\end{tabular}
rotors introducing second-order resonances occur. The
TABLE 1: The values of parameters used in the simulation.

corresponding frequency components shown in Figures 6(e) to $6(\mathrm{~h})$ could prove the results.

From Figure 6, we could see that, around the natural resonance regions, the natural frequency components of the low- or high-pressure rotors' responses dominate while the nonresonant frequency components are weak obviously. It is noting that, in the high-pressure rotor introduced first-order resonance region, a weak high-frequency component of $2 f_{2}$ exists. Also, a weak $2 f_{2}-f_{1}$ combination frequency component merges in the second-order resonance region. Both of them are introduced by the nonlinear terms of the intershaft bearing.

When the clearance of the intershaft bearing increases, the resonance peaks move to the low-frequency direction to a relatively small extent. Noting that, in the case of $f_{1}=86.9 \mathrm{~Hz}$, in which $f_{2}=113 \mathrm{~Hz}$, with the clearance increase, an obvious combination frequency component of $f=2 f_{1}-f_{2}$ appears. As shown in Figure 7, compared with the amplitudes of main excitation frequencies $f_{1}$ and $f_{2}$, the amplitude of the combination frequency component is relatively large to be considered. This indicates that the system has a combination resonance region here.

The effects of the change of bearing clearance on the equivalent stiffness of the intershaft bearing are illustrated in 


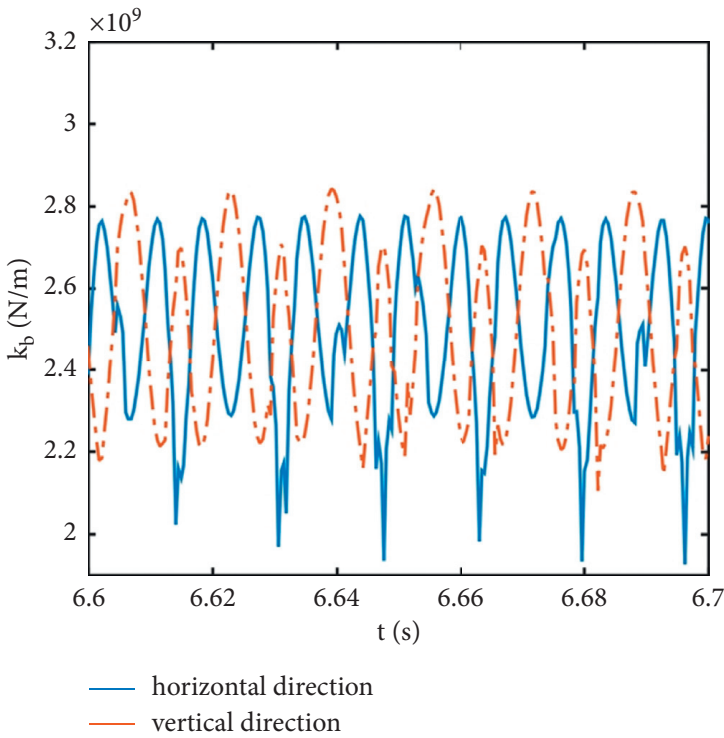

(a)

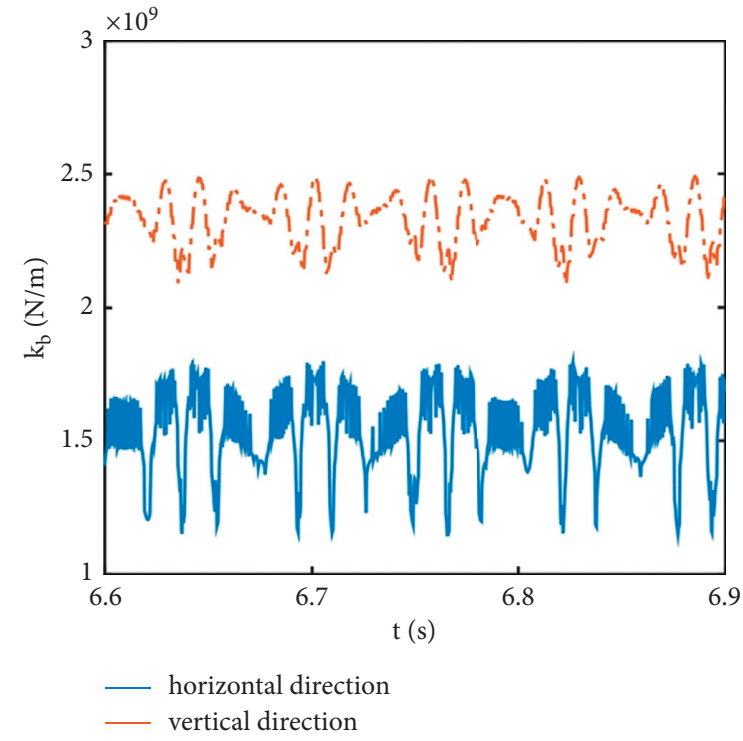

(b)

Figure 3: The time-varying stiffness feather of the intershaft bearing. (a) $f_{1}=46.2 \mathrm{~Hz}$ and (b) $f_{1}=51 \mathrm{~Hz}$.

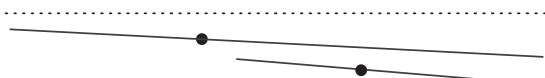

(a)

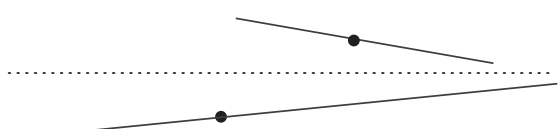

(b)

Figure 4: The first two orders of models of the dual-rotor. (a) The first order and (b) the second order.

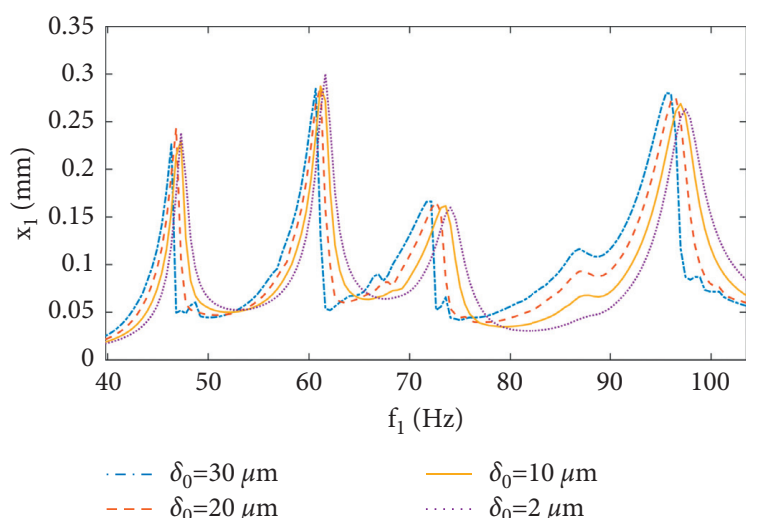

(a)

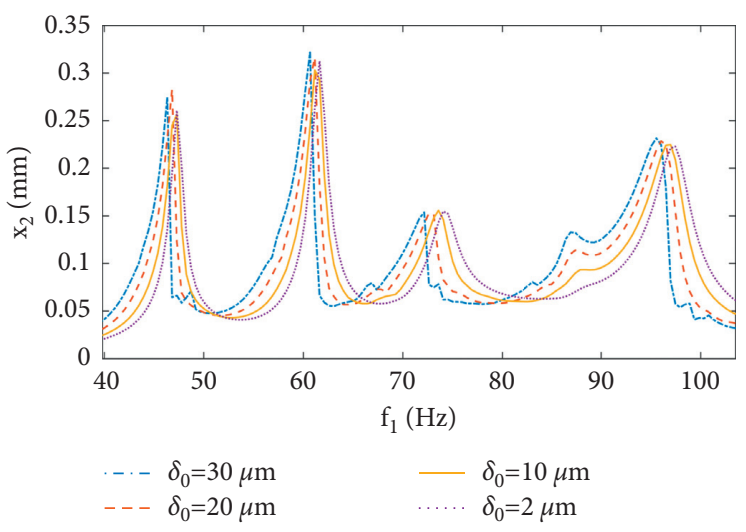

(b)

FIGURE 5: Amplitude-frequency curves of horizontal direction with different clearances. (a) For low-pressure rotor and (b) for high-pressure rotor.

Figure 8. The change rule of the horizontal stiffness with $f_{1}$ follows the same tread of the amplitude-frequency curve, which is shown in Figure 5. In the resonance region, the vertical equivalent stiffness equals the horizontal one, which can be indicated by the comparison of the blue line and the orange line in Figure 8(a) and shown in Figure 3(a). In the nonresonant region, the trend of the vertical stiffness is opposite to the horizontal one, and the value is bigger, which is shown in Figures 8(b) and 3(b).

The larger equivalent stiffness in the vertical direction is caused by gravity, and the equivalent stiffness tends to return to the horizontal direction at the resonance peak, indicating that the effect of gravity at the resonance peak is smaller than the eccentric effect of the unbalanced mass. In the 

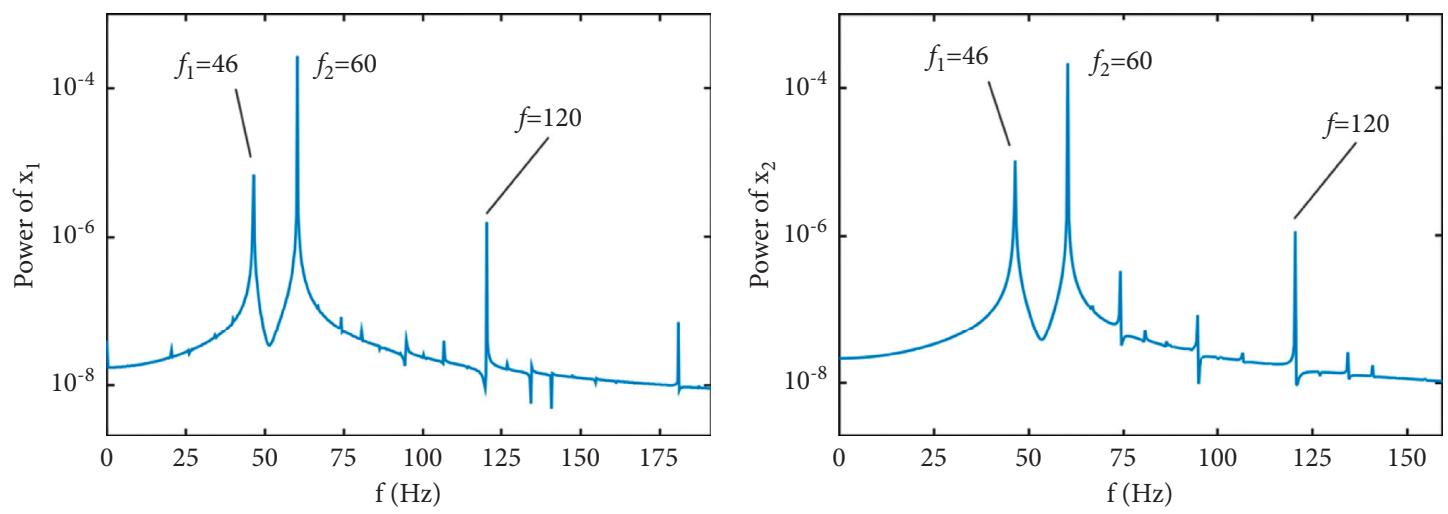

(a)

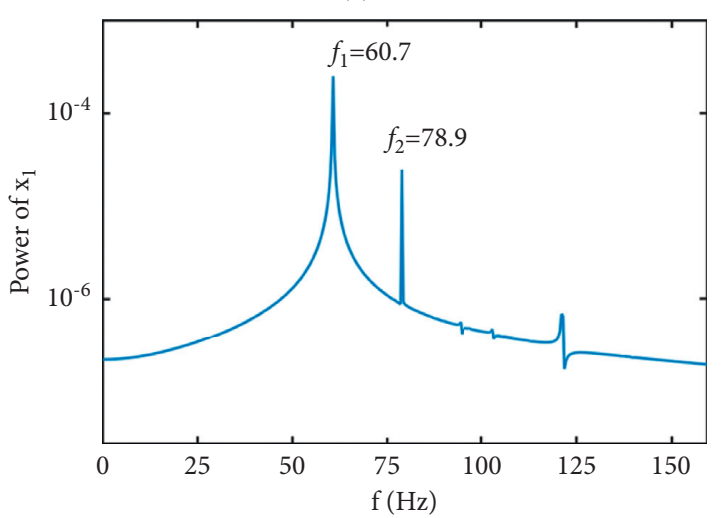

(b)

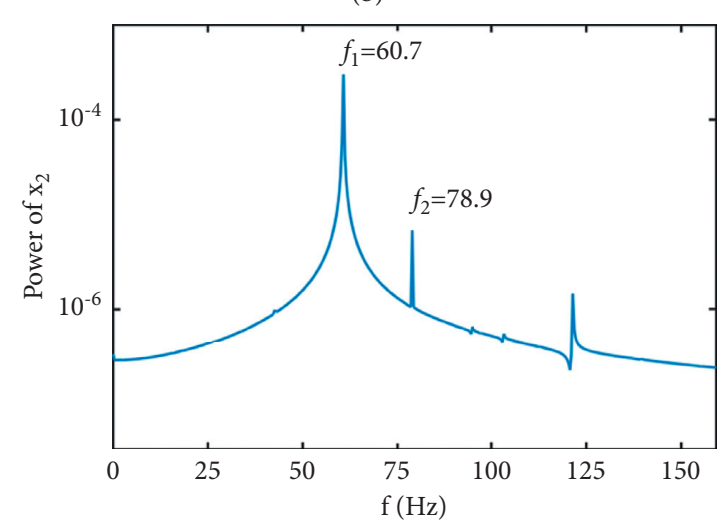

(c)

(d)
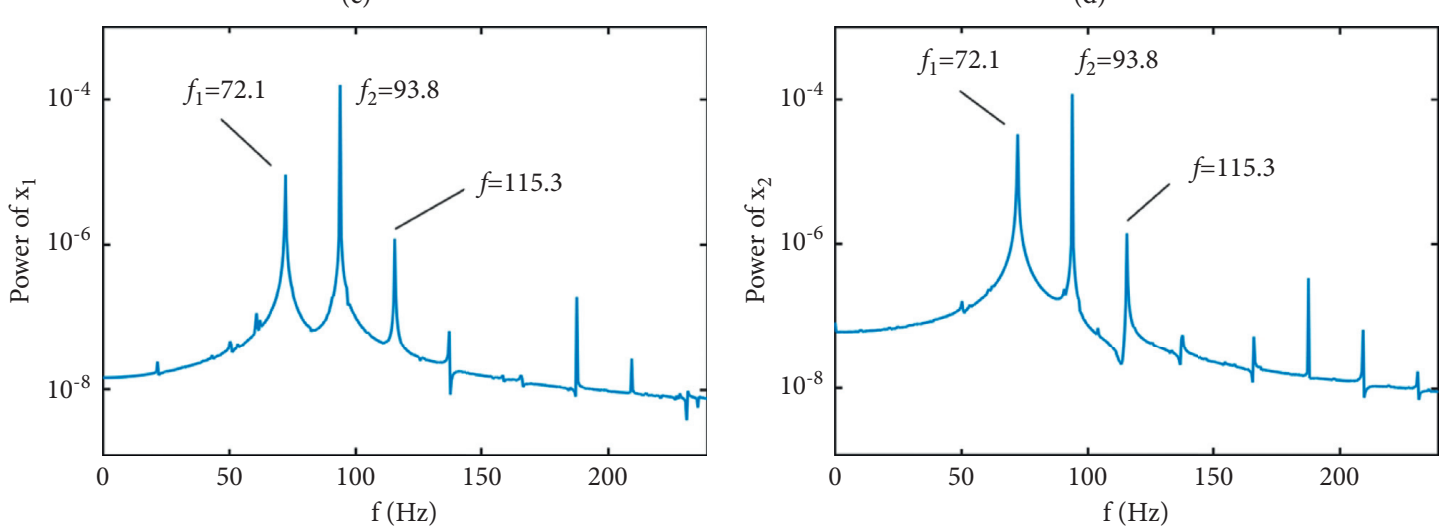

(e)

(f)

FIgURE 6: Continued. 


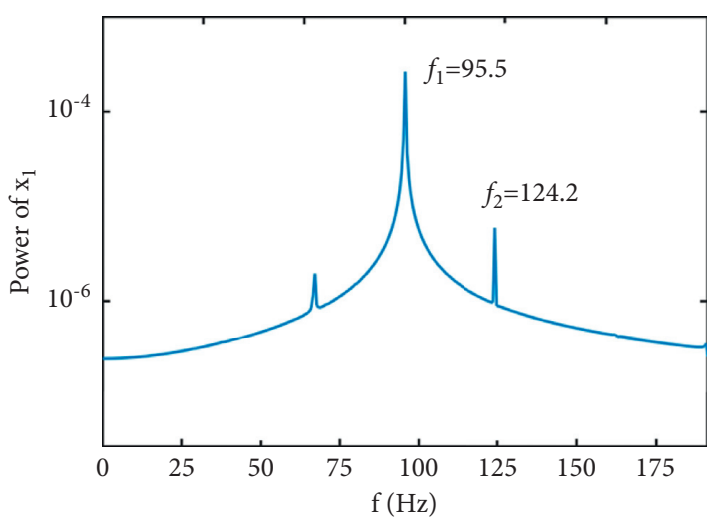

(g)

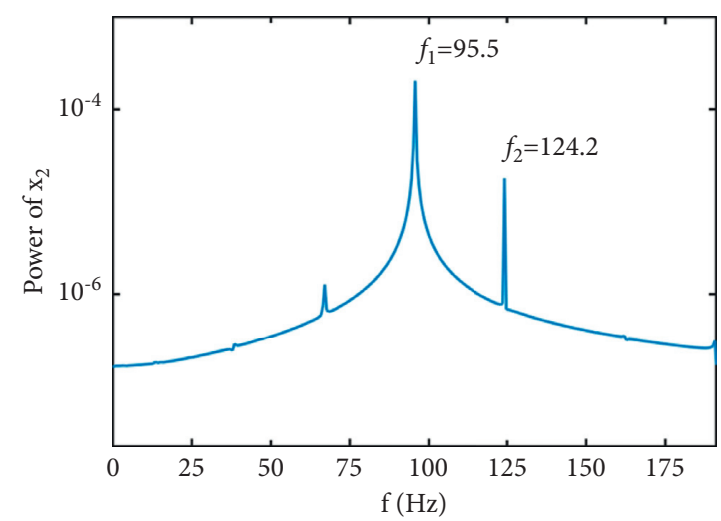

(h)

FiguRE 6: Spectrum of the responses of the low- and high-pressure rotors in the horizontal direction at different frequency points. (a) $f_{1}=46.3 \mathrm{~Hz}$; (b) $f_{1}=46.3 \mathrm{~Hz}$; (c) $f_{1}=60.7 \mathrm{~Hz}$; (d) $f_{1}=60.7 \mathrm{~Hz}$; (e) $f_{1}=72.1 \mathrm{~Hz}$; (f) $f_{1}=72.1 \mathrm{~Hz}$; (g) $f_{1}=95.5 \mathrm{~Hz}$; (h) $f_{1}=95.5 \mathrm{~Hz}$.

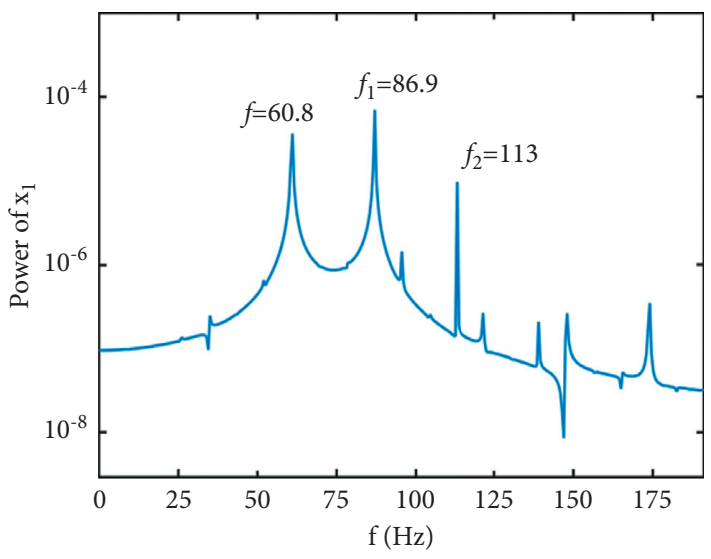

(a)

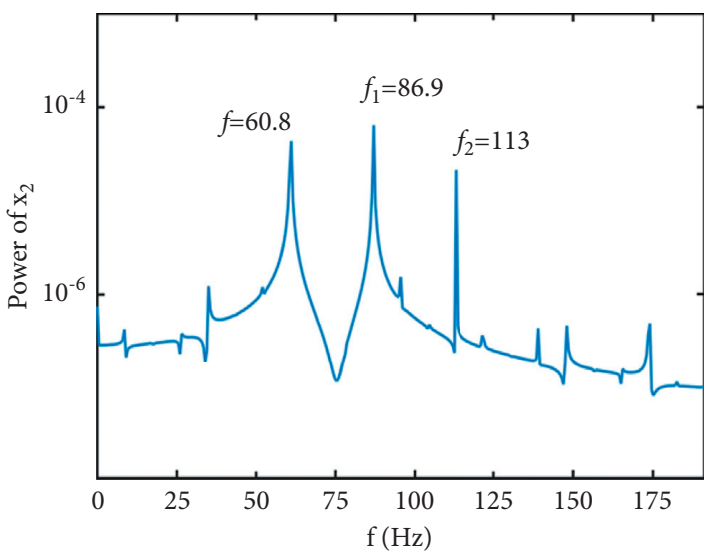

(b)

FIGURE 7: Spectrum of responses when combination frequency resonance occurs. (a) Low-pressure rotor and (b) high-pressure rotor.

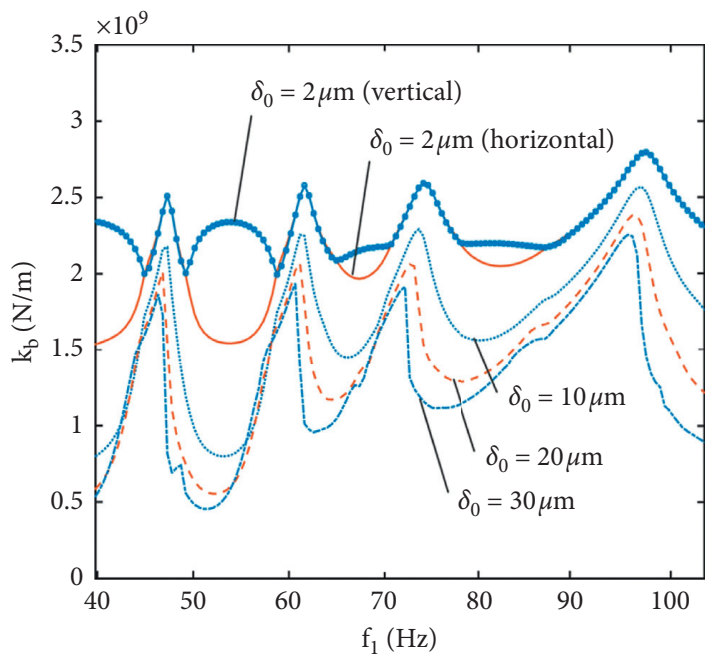

(a)

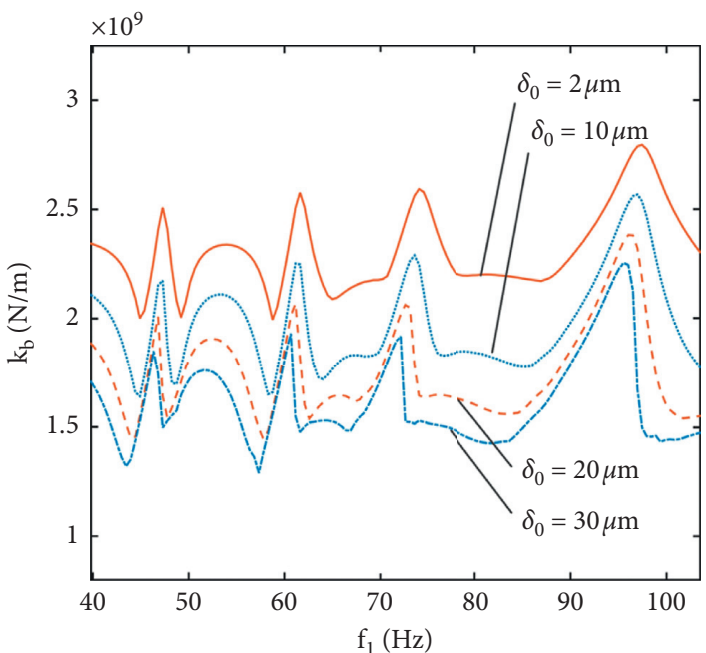

(b)

FIGURE 8: Equivalent stiffness of intershaft with different clearances. 
nonresonant situation, the influence of gravity on the equivalent stiffness is more obvious. As the clearance increases, both the horizontal and vertical stiffnesses decrease.

Compared with the results of ball bearing [28], almost periodic and chaos solutions do not exist when the roller bearing type is used as the intershaft bearing. That is to say, the 10/9 order nonlinear effect contained in the roller bearing is not strong. In the case of small clearances, the main resonance behavior can be expected as a linear one. And in simplification calculation, the support can be assumed as a linear spring.

3.2. Analysis of the Implemented Position. In the simplified model shown in Figure 1, besides the intershaft bearing, the SFD can be implemented onto other bearings, including the front and rear support of the low-pressure shaft and the front support of the high-pressure shaft to control the vibration behaviors. Different implementation positions would lead to different results.

Figure 9 shows the amplitude-frequency response when the SFD with different clearances being installed on the front support of the low-pressure shaft. The dense dotted line 'a' in Figure 9 represents the situation when the SFD is not installed. The installation of the SFD on the front low-pressure shaft has the effect of suppressing the amplitude of all resonance peaks, especially for the two peaks of the secondorder resonances. In region $f_{1}=95.5 \mathrm{~Hz}$, there is a hysteresis loop, which means a jump phenomenon occurs. With the decrease of the clearance of the SFD, the hysteresis loop is reduced accordingly. However, the small change of clearance would lead the resonance band wide, at $f_{1}=95.9 \mathrm{~Hz}$.

Figure 10 shows the amplitude-frequency responses when the SFD with different clearances being installed on the rear support of the low-pressure shaft. The dense dotted line ' $a$ ' in Figure 10 represents the situation when the SFD is not installed. For the first-order resonance, the rear low-pressure SFD can reduce the amplitude and increase the effect with the decrease of the clearance. But in the second-order resonant regions, the amplitudes are almost the same as SFD or not.

Figure 11 shows the amplitude-frequency response when the SFD with different clearances being installed on the front support of the high-pressure shaft. The dense point curve 'a' in Figure 11 shows the case when the SFD is not applied. This position has effects on both first-order and second-order resonances. As the clearance decreases, the corresponding amplitude becomes smaller.

In the case of adding SFDs onto bearings, the selection of the position should refer to the vibration mode of the dualrotor, and the parameters of the SFDs should be optimized to achieve better performances.

3.2.1. Analysis of the Number of SFDs. The effects of the application of SFD when two or even three SFDs are implemented simultaneously are discussed in this section. Figure 12 shows the amplitude-frequency curves when two SFDs are implemented onto the front and rear support of the

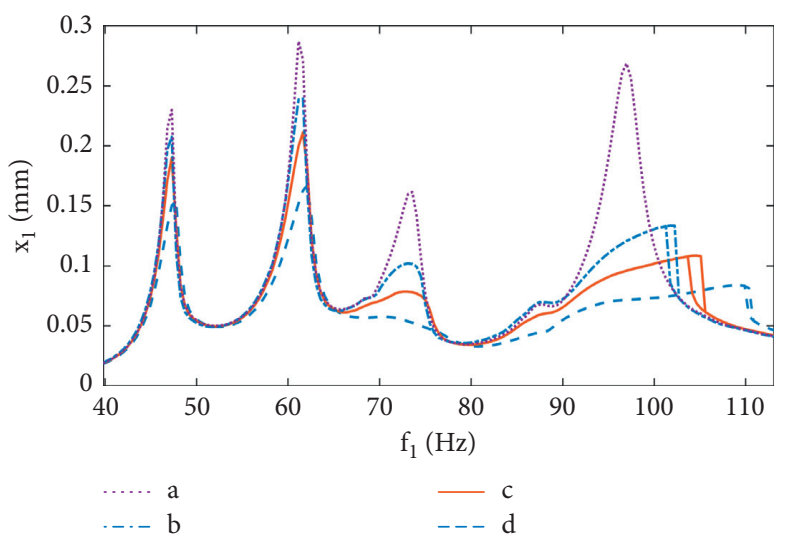

FIGURE 9: Amplitude-frequency curves when front low-pressure SFD is implemented (a: no SFD, b: $0.25 \mathrm{~mm}$, c: $0.20 \mathrm{~mm}$, d: $0.15 \mathrm{~mm}$ ).

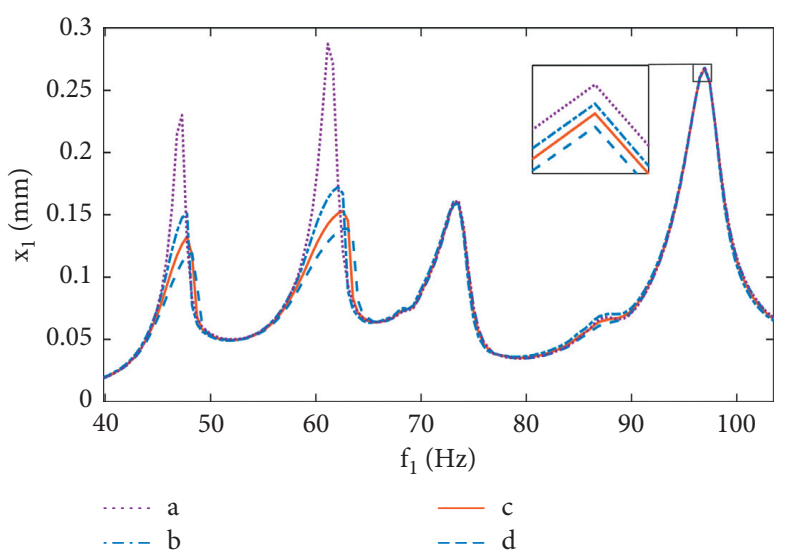

FIgURE 10: Amplitude-frequency curves when rear low-pressure SFD is implemented (a: no SFD, b: $0.25 \mathrm{~mm}, c: 0.20 \mathrm{~mm}$, d: $0.15 \mathrm{~mm}$ ).

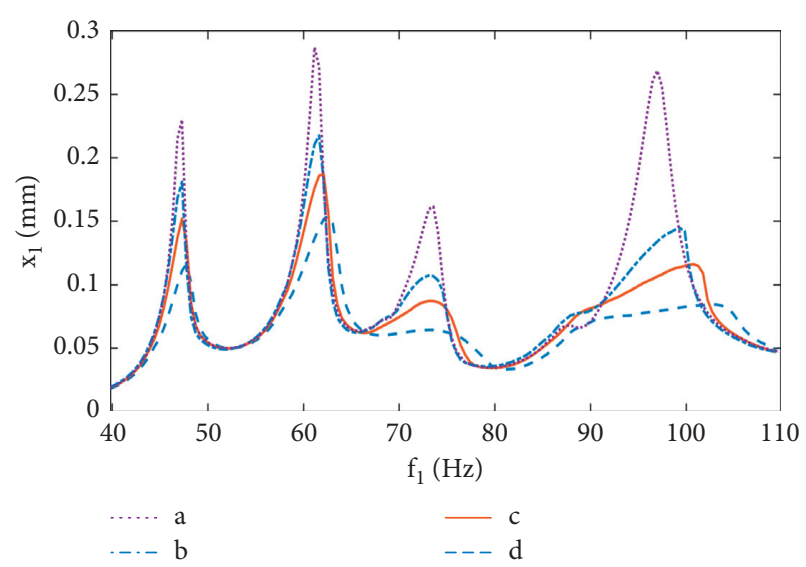

FIgURE 11: Amplitude-frequency curves when front high-pressure SFD is implemented (a: no SFD, b: $0.25 \mathrm{~mm}, \mathrm{c}: 0.20 \mathrm{~mm}, \mathrm{~d}$ : $0.15 \mathrm{~mm})$.

low-pressure shaft with different clearances. The dense dotted line (line ' $a$ ' in Figure 12) gives the results when no additional SFD is implemented. The other three lines give 


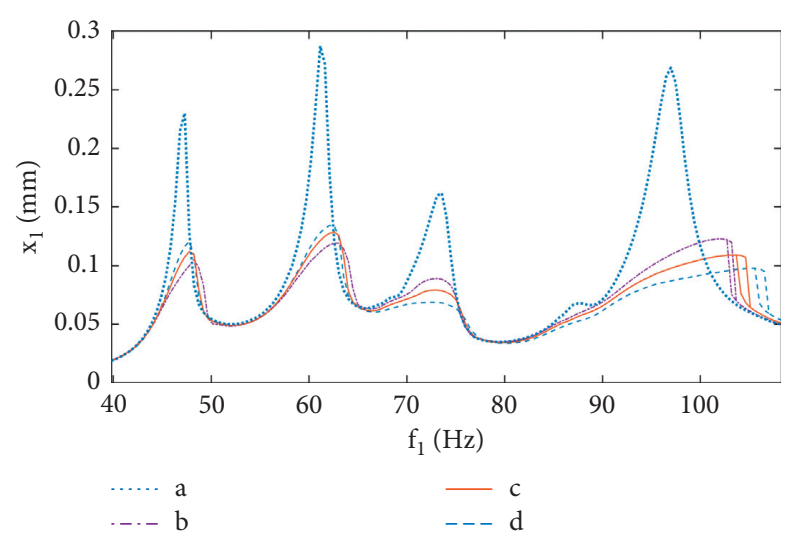

FIgURE 12: Amplitude-frequency curves when two SFDs are implemented on the front and the rear bearing of the low-pressure shaft with different sets of clearances (a: no SFD, b: $0.22 \mathrm{~mm}$ and $0.18 \mathrm{~mm}, \mathrm{c}: 0.2 \mathrm{~mm}$ and $0.2 \mathrm{~mm}, \mathrm{~d}: 0.18 \mathrm{~mm}$ and $0.22 \mathrm{~mm}$ ).

the results when two SFDs are implemented on the front and the rear bearings of the low-pressure shaft, only with different sets of clearances of these two SFDs. Line ' $b$ ' corresponds to the set of $0.22 \mathrm{~mm}$ and $0.18 \mathrm{~mm}$. Line ' $c$ ' corresponds to the set of $0.20 \mathrm{~mm}$ and $0.20 \mathrm{~mm}$. Line ' $\mathrm{d}$ ' corresponds to the set of $0.18 \mathrm{~mm}$ and $0.22 \mathrm{~mm}$. Comparing these three lines, we could find that the amplitude of the first-order resonant peak is insensitive to the change of the value of clearance of front SFD, while the amplitude of the second-order resonant peak is insensitive to the change of clearance of the rear SFD. The hysteresis loops appearing in the second-order resonance excited by the low-pressure rotor keep their size as the clearances have almost equal effects. Figure 13 gives the comparison results of the cases that only one SFD is implemented in the front bearing or the rear bearing of the low-pressure rotor and two SFDs are implemented simultaneously. The first-order resonances are mainly controlled by the rear SFD, while the peak values of the second-order resonance are affected by the front SFD. The hysteresis jump characteristic is introduced by the front SFD.

Following the same analysis manner, the amplitudefrequency curves and their comparisons when two SFDs are implemented in the front bearing of low-pressure and the front bearing of high-pressure and two SFDs are implemented in the rear bearing of low-pressure and front bearing of high-pressure are shown from Figure 14.

Figure 14 shows the amplitude-frequency curves when the front bearings of low- and high-pressure shaft are implemented with different clearance sets. Line 'a' in Figure 14 gives the result when no SFD is added as a comparison example. The first-order resonance is not affected by the change of the clearance. The second-order resonance peaks decrease slightly with the decrease of the clearance of the high-pressure front SFD.

Figure 15 gives the comparison results of two SFDs being applied and only one being implemented. From the comparisons, the effects of two applied SFDs are no better than one applied SFD. And with the comparisons conducted in Figure 14, the parameters of the clearance are not determined factor in this case.

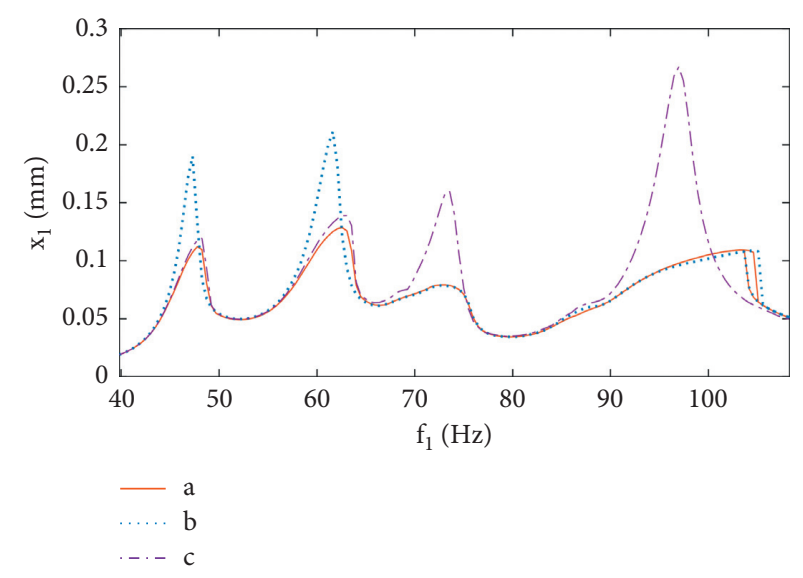

FIgURE 13: Comparisons of different SFD implemental configurations (a: two SFDs, b: one front low-pressure SFD, c: one rear low-pressure SFD).

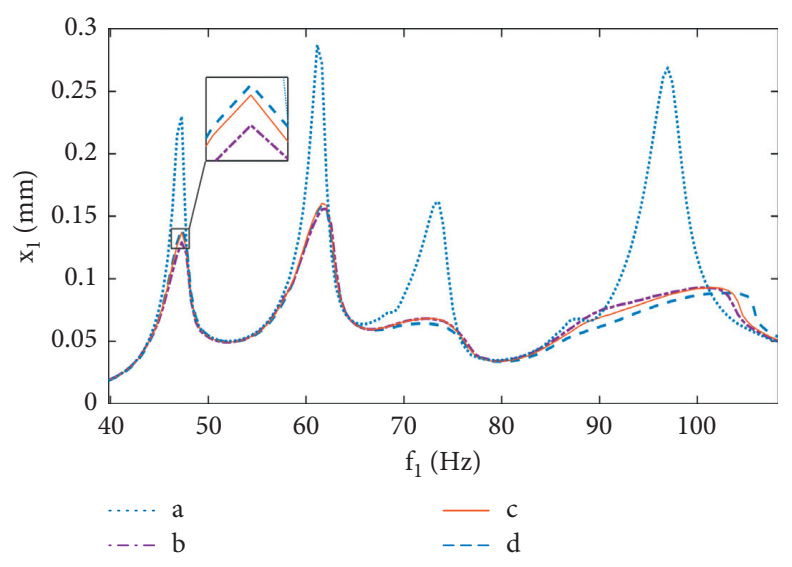

Figure 14: Amplitude-frequency curves when two SFDs are implemented on the front bearings of the low- and high-pressure shafts with different sets of clearances (a: no SFD, b: $0.22 \mathrm{~mm}$ and $0.18 \mathrm{~mm}, \mathrm{c}: 0.2 \mathrm{~mm}$ and $0.2 \mathrm{~mm}, \mathrm{~d}: 0.18 \mathrm{~mm}$ and $0.22 \mathrm{~mm}$ ).

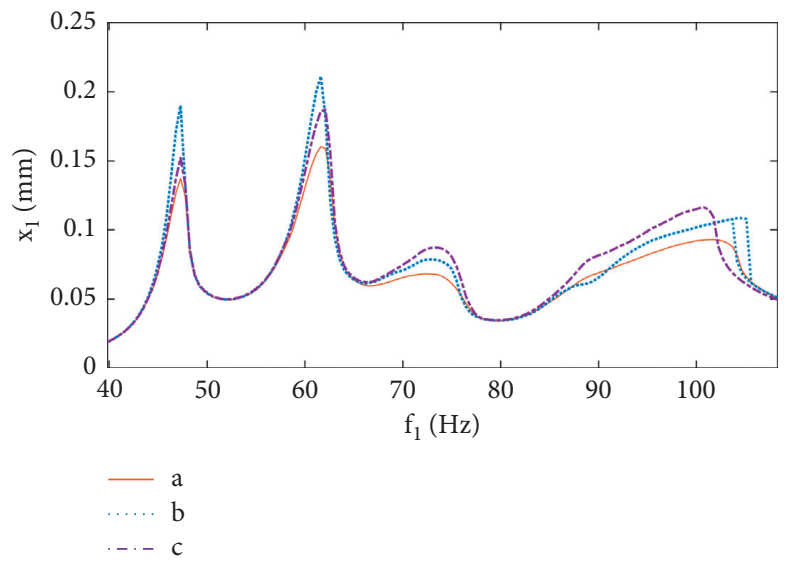

Figure 15: Comparisons of different SFD implemental configurations (a: two SFDs, b: one front low-pressure SFD, c: one front high-pressure SFD). 


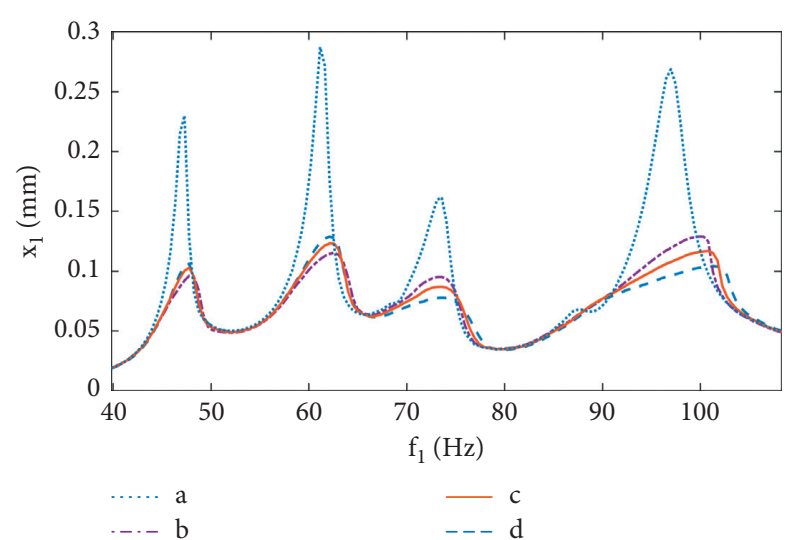

FIGURE 16: Amplitude-frequency curves when two SFDs are implemented on the rear bearing of the low-pressure shaft and the front bearing of the high-pressure shaft with different sets of clearances (a: no SFD, b: $0.22 \mathrm{~mm}$ and $0.18 \mathrm{~mm}, \mathrm{c}: 0.2 \mathrm{~mm}$ and $0.2 \mathrm{~mm}$, d: $0.18 \mathrm{~mm}$ and $0.22 \mathrm{~mm}$ ).

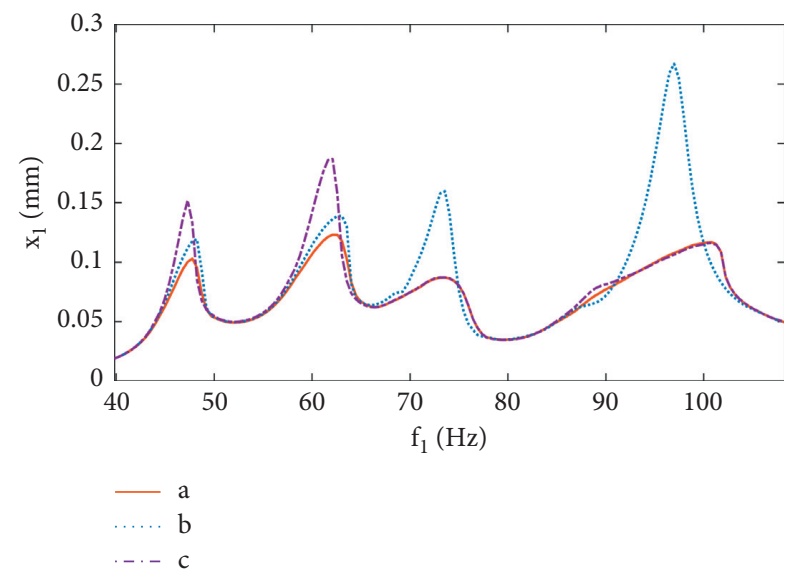

Figure 17: Comparisons of different SFD implemental configurations (a: two SFDs, b: one rear low-pressure SFD, c: one front high-pressure SFD).

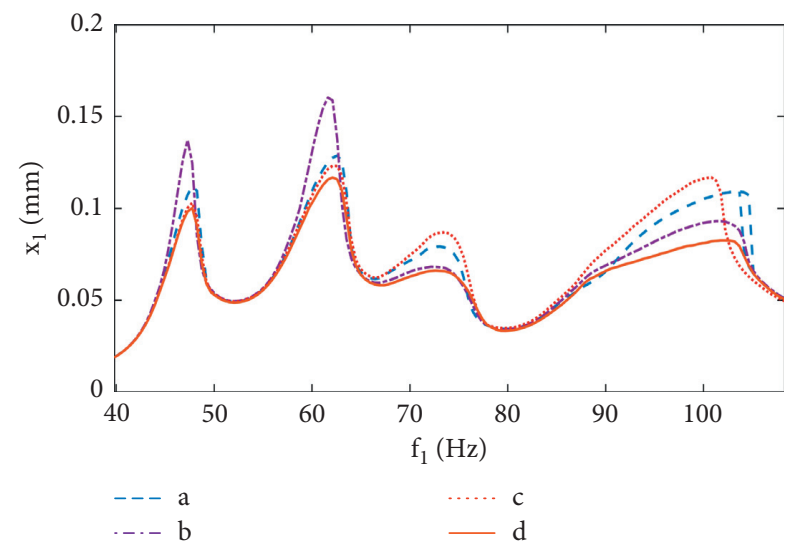

FIGURE 18: Comparisons of effects of vibration suppression with different SFD configurations (a: two supports of the low-pressure shaft, b: front support of low-pressure shaft and front support of high-pressure shaft, c: rear support of low-pressure shaft and front support of high-pressure shaft, d: all three supports.).

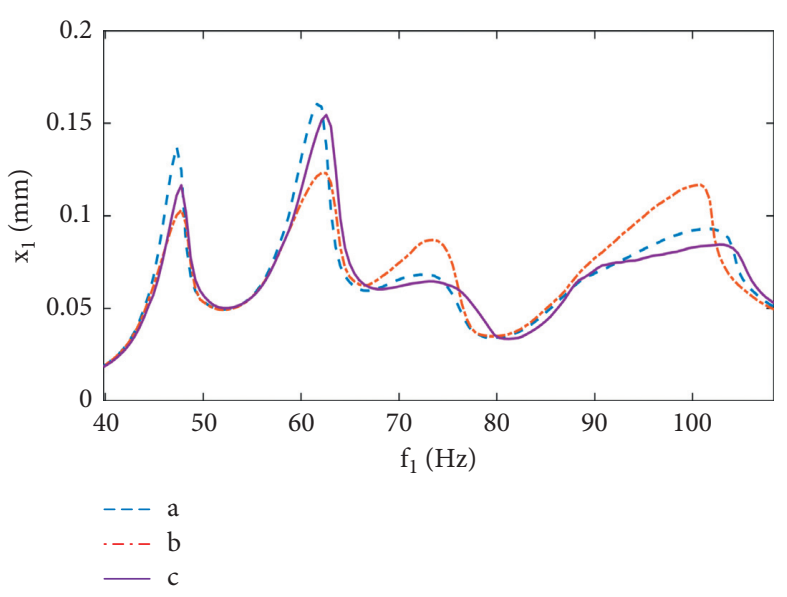

FIGURE 19: Comparison of effects of vibration suppression with different SFD configurations (a: front support of low-pressure shaft and front support of high-pressure shaft, b: rear support of lowpressure shaft and front support of high-pressure shaft, c: only front support of high-pressure shaft with clearance of $0.15 \mathrm{~mm}$.).

Similarly, Figure 16 shows amplitude-frequency curves as the low-pressure rear SFD and the high-pressure front SFD are mounted. For the first-order resonance peaks, the amplitude decreases with the decrease of clearance of rear low-pressure SFD, and for the second-order resonance peaks, they decrease with the decrease of the front highpressure one. Figure 17 gives the comparisons of different numbers of SFDs being applied. Two-SFD case takes the advantage of single uses, making the amplitude control effect more obvious.

Figure 18 illustrates the amplitude-frequency curve of response when all three bearings are with SFDs and compares it with three cases of two implemented SFDs each. The vibration suppression effects with three SFD are the best obviously. However, this configuration increases the cost and complexity of the whole system. Sometimes, if certain aims are highlighted, an easy configuration can be adopted. For example, as shown in Figure 19, one SFD with an optimized parameter can achieve the same effects as two SFDs.

\section{Conclusions and Discussions}

In this work, a rigid dual-rotor intershaft bearing system with squeeze film damper's implementation is investigated. The models of the dual-rotor, roller bearing, and oil film force are established and concatenated together. The numerical simulation is conducted and corresponding amplitude-frequency curves are got for comparison and analysis. Through the results, the conclusions can be drawn as follows:

(1) The nonlinearity of the intershaft bearing causes a weak frequency component of double high-pressure rotor speed $\left(2 f_{2}\right)$ and causes a weak combination frequency component of $2 f_{2}-f_{1}$ in the highpressure rotor excited second-order resonance region. As the 10/9 order of nonlinearity introduced by 
intershaft bearing is not huge, the amplitudes of nonlinear components are small.

(2) The change trend of the equivalent stiffness in the horizontal direction of the intershaft bearing is consistent with the amplitude-frequency curve, while the vertical equivalent stiffness is consistent with the amplitude-frequency response in the resonance region, and the change trend is opposite to the amplitude-frequency response in the nonresonant region. Therefore, in the resonance zone, the horizontal and the equivalent stiffness in the vertical direction is almost equal, but in the nonresonant region, the equivalent stiffness in the vertical direction is bigger than the equivalent stiffness in the horizontal direction.

(3) Different SFD implementation positions and numbers have different effects on responses. The rear lowpressure affects the first-order resonance a lot but has almost no effect on the second-order resonance. The front low-pressure SFD suppresses the second-order resonance. The front SFD of the high-pressure shaft has both damping effects on the primary and secondary main resonances. Multiple SFDs can be used together to obtain the advantages of a single damper.

It is noting that, in this work, besides the intershaft bearing, there are only three bearings. A more complicated system with more supports will lead the investigation of this kind of system to be more complex. Thus, to avoid huge calculation, analytical analysis can be conducted in further study.

\section{Data Availability}

(1) No public dataset was used in the manuscript; all the data used to draw the figures and support the conclusions of the manuscript are generated by calculating the model established in the manuscript. (2) The calculation result data used to support the findings of this study are available from the first author (Huizheng Chen) upon request, who can be contacted at chenhz@sdnu.edu.cn. (3) All the data will be released, including codes, after acceptance of the manuscript.

\section{Conflicts of Interest}

On behalf of all authors, the corresponding author states that there are no conflicts of interest.

\section{Acknowledgments}

This work was supported by the National Natural Science Foundation of China (Grant nos. 12102234, 11502161, and 11902184), Shandong Provincial Natural Science Foundation, China (Grant nos. ZR2018BA021 and ZR2018QA005), and the China Postdoctoral Science Foundation (Grant no. 2017M622259).

\section{References}

[1] O. Schmitz, H. Klingels, and P. Kufner, "Aero engine concepts beyond 2030: Part 1-the steam injecting and recovering aero engine," Journal of Engineering for Gas Turbines \& Power, vol. 143, no. 2, Article ID 021001, 2021.

[2] S. Kaiser, O. Schmitz, and H. Klingels, "Aero engine concepts beyond 2030: Part 2-the free-piston composite cycle engine," Journal of Engineering for Gas Turbines \& Power, vol. 143, no. 2, Article ID 021002, 2021.

[3] O. Schmitz, S. Kaiser, H. Klingels et al., "Aero engine concepts beyond 2030: Part 3-experimental demonstration of technological feasibility," Journal of Engineering for Gas Turbines \& Power, vol. 143, no. 2, Article ID 021003, 2021.

[4] B. Maschler, H. Vietz, N. Jazdi, and M. Weyrich, "Continual learning of fault prediction for turbofan engines using deep learning with elastic weight consolidation," in Proceeding of the 2020 25th IEEE international conference on emerging technologies and factory automation (ETFA), vol. 1, pp. 959-966, IEEE, Vienna, Austria,, 8-11 Sept. 2020.

[5] D. Pavlenko, Y. Dvirnyk, and R. Przysowa, "Advanced materials and technologies for compressor blades of small turbofan engines," Aerospace, vol. 8, no. 1, p. 1, 2021.

[6] D. Cheng, L. Liu, and Z. Yu, "A nonlinear h set-point control method for turbofan engines with disturbances," International Journal of Control, Automation and Systems, vol. 19, no. 9, pp. 1-13, 2021.

[7] D. Cheng, L. Liu, and Z. Yu, "Cnn-based intelligent faulttolerant control design for turbofan engines with actuator faults," IEEE Access, vol. 9, pp. 28122-28139, 2021.

[8] H. H. Omar, V. S. Kuz'michev, and A. Y. Tkachenko, "Optimization the main thermodynamics parameters of the aviation turbofan engines with heat recovery in the aircraft system," Journal of Physics: Conference Series, vol. 1745, no. 1, Article ID 012105, 2021.

[9] H. Omar, V. S. Kuz'michev, and A. Y. Tkachenko, "Improving the efficiency of aviation turbofan engines by using an intercooler and a recuperative heat exchanger," VESTNIK of Samara University. Aerospace and Mechanical Engineering, vol. 19, no. 3, pp. 85-99, 2020.

[10] P. Gao, Y. Chen, and L. Hou, "Nonlinear thermal behaviors of the inter-shaft bearing in a dual-rotor system subjected to the dynamic load," Nonlinear Dynamics, vol. 101, no. 1 , pp. 191-209, 2020.

[11] T. Gao and S. Cao, "Paroxysmal impulse vibration phenomena and mechanism of a dual-rotor system with an outer raceway defect of the inter-shaft bearing," Mechanical Systems and Signal Processing, vol. 157, Article ID 107730, 2021.

[12] K. Shaik and B. K. Dutta, "Tuning criteria of nonlinear flexible rotor mounted on squeeze film damper using analytical approach," Journal of Vibration Engineering \& Technologies, vol. 9, no. 2, pp. 325-339, 2021.

[13] K. Shaik and B. K. Dutta, "Stability analysis of horizontal symmetric flexible rotor mounted on hydrodynamic bearing and squeeze film damper using analytical approach," Tribology International, vol. 158, Article ID 106924, 2021.

[14] W. Zhang, B. Han, X. Li, J. Sun, and Q. Ding, "Multi-objective system optimization method and experimental validation of a centralized squeeze film damper using a cell mapping method considering dynamic constraints," Engineering Optimization, vol. 53, no. 6, pp. 941-961, 2021.

[15] W. Zheng, S. Pei, Q. Zhang, and J. Hong, "Experimental and theoretical results of the performance of controllable 
clearance squeeze film damper on reducing the critical amplitude," Tribology International, Article ID 107155, 2021.

[16] X. Ma, H. Ma, H. Qin, X. Guo, C. Zhao, and M. Yu, "Nonlinear vibration response characteristics of a dual-rotorbearing system with squeeze film damper," Chinese Journal of Aeronautics, vol. 34, no. 10, pp. 128-147, 2021.

[17] T. Fan and K. Behdinan, "An analytical model for open-ended squeeze film damper with a circumferential central groove," Proceedings of the Institution of Mechanical Engineers - Part J: Journal of Engineering Tribology, vol. 235, no. 10, pp. 2110-2121, 2021.

[18] D. Shin, A. B. Palazzolo, and X. Tong, "Squeeze film damper suppression of thermal bow-morton effect instability," Journal of Engineering for Gas Turbines \& Power, vol. 142, no. 12, Article ID 121013, 2020.

[19] X. Chen, X. Gan, and G. Ren, "Dynamic modeling and nonlinear analysis of a rotor system supported by squeeze film damper with variable static eccentricity under aircraft turning maneuver," Journal of Sound and Vibration, vol. 485, Article ID 115551, 2020.

[20] V. Iacobellis, K. Behdinan, D. Chan, and D. Beamish, "Experimental investigation of the effects of squeeze film damper design on highspeed rotor system," Turbo Expo: Power for Land, Sea, and Air, vol. 84225, Article ID V10BT29A001, 2020.

[21] W. Li, C. Braman, B. Hantz, M. Thorat, and B. Pettinato, "Squeeze film damper bearing with double-ended beam springs: Part ii-experimental validation," Turbo Expo: Power for Land, Sea, and Air, vol. 84218, Article ID V10AT25A026, 2020.

[22] G. Curti, F. A. Raffa, and F. Vatta, "An analytical approach to the dynamics of rotating shafts," Meccanica, vol. 27, no. 4, pp. 285-292, 1992.

[23] N. Herisanu and V. Marinca, "An efficient analytical approach to investigate the dynamics of a misaligned multirotor system," Mathematics, vol. 8, no. 7, p. 1083, 2020.

[24] W. Fan, Y. Yang, and X. Su, "Dynamic modeling and vibration characteristics analysis of transmission process for dual-motor coupling drive system," Symmetry, vol. 12, no. 7, p. 1171, 2020.

[25] N. A. H. Tsuha and K. L. Cavalca, "Stiffness and damping of elastohydrodynamic line contact applied to cylindrical roller bearing dynamic model," Journal of Sound and Vibration, vol. 481, Article ID 115444, 2020.

[26] F. Weber and M. Maślanka, "Precise stiffness and damping emulation with $\mathrm{mr}$ dampers and its application to semi-active tuned mass dampers of wolgograd bridge," Smart Materials and Structures, vol. 23, no. 1, Article ID 015019, 2013.

[27] S. Krenk and S. R. K. Nielsen, "Vibrations of a shallow cable with a viscous damper," Proceedings of the Royal Society of London. Series A: Mathematical, Physical and Engineering Sciences, vol. 458, no. 2018, pp. 339-357, 2002.

[28] H. Chen, S. Zhong, Z. Lu, Y. Chen, J. Han, and C. Wang, "Analysis on multi-mode nonlinear resonance and jump behavior of an asymmetric rolling bearing rotor," Archive of Applied Mechanics, vol. 91, pp. 2991-3009, 2021. 